Research Article

\title{
Experimental Study on Seismic Behavior of Composite Shear Wall with Inclined Bars
}

\author{
Y. L. Wang $(\mathbb{D}$, D. D. Hu $\mathbb{D}$, and B. Fang $\mathbb{C}$ \\ Department of Civil Engineering, Tianjin Chengjian University, Tianjin 300384, China \\ Correspondence should be addressed to D. D. Hu; lyjn@tcu.edu.cn
}

Received 21 April 2021; Accepted 16 July 2021; Published 26 October 2021

Academic Editor: Kang Shao-Bo

Copyright (C) 2021 Y. L. Wang et al. This is an open access article distributed under the Creative Commons Attribution License, which permits unrestricted use, distribution, and reproduction in any medium, provided the original work is properly cited.

\begin{abstract}
The composite shear wall is the core component of the thermal insulation integrated structure, which is a load-bearing shear wall with good thermal insulation, sound insulation, and seismic resistance. To improve the applicable height of the composite shear wall structure, a cohesive sandwich heat-insulation composite shear wall with door frame inclined tendon and diamond-shaped inclined tendon is proposed, and the quasistatic force of four 1/2-scale shear wall test specimens is carried out. Different specimens are analyzed, including failure modes, hysteresis curves, skeleton curves, stiffness degradation, ductility performance, and energy dissipation capacity. The following conclusions are drawn: the failure modes of the specimens are bending and shear failure; the ultimate strength and deformation performance of the composite wall close to the solid wall; the composite wall with the door frame inclined tendon can effectively delay the wall cracking and improve the bearing capacity and energy consumption capacity of the composite wall; the configuration of the diamond-shaped inclined tendon improves the ductility and energy dissipation capacity of the composite wall.
\end{abstract}

\section{Introduction}

The composite wall is formed by two layers of wire mesh frame connected by horizontal inclined tendons, which are the thermal insulating material in the middle, and concrete is poured on both sides. The integration and thermal insulation of the building structure is realized, which has the advantages of extending the life of the thermal insulation layer, avoiding later maintenance work and reducing construction waste [1]. The researches on the existing composite shear wall at home and abroad show that the composite wall connected by inclined tendons has good working ability and its stress performance is close to or better than that of the ordinary solid shear wall [2-6]. Cao et al. $[7,8]$ put forward the concept of concealed bracing and carried out a test analysis on the shear wall with concealed bracing, and the test results showed that the shear wall with concealed bracing had better comprehensive stress performance than the ordinary shear wall. Inspired by Wang et al. research on the seismic performance of shearing wall with concealed bracing [9-11], it is proposed to simplify the concealed bracing with inclined tendons to be applied to the composite wall structure system, to simplify the construction method and the amount of steel used, and to carry out seismic performance test research and theoretical analysis of the improved composite wall. Goel et al. [12] compared the dynamic response of stiffened steel plate, sandwich foam plate, and stiffened sandwich foam plate. The results show that the sandwich foam plate has better impact load. Hamed [13] investigated the behavior of precast concrete sandwich panels (PCSPs) made with truss shear connectors, and a computational model equation is proposed to describe the complex structure behavior of PCSPs. Qian et al. [14] studied six double flange web composite walls and concrete-filled steel tubular T-shaped composite walls under axial compression and transverse cyclic loading and concluded that the composite wall was ductile bending failure. Qin et al. [15] proposed a new type of steel truss composed of angle steel and bending steel. Full scale tests were carried out on three kinds of plate thickness specimens, and the influence of plate thickness on structural performance was discussed in detail. Sabouri-Ghomi et al. [16] proposed an improved analytical 
formula based on the partial interaction theory, which considered a new type of load and the cracking of concrete, so as to approach the real situation. Kong et al. [17] studied the double steel plate composite wall and reinforced concrete raft foundation, mainly focused on the wall connection. In this paper, a new type of tie bar with inner web instead of tie bar is proposed. Qin et al. [18] studied the structural behavior of L-type double skin composite wall under axial compression and biaxial bending. The experimental results of load displacement response, buckling behavior, and stiffness of five eccentrically compressed specimens are discussed, and a method for calculating the bidirectional effective bending moment is proposed. However, the existing composite wall is only suitable for low rise buildings. With high-rise as the mainstream, it is necessary to improve the mechanical performance of composite wall structure to meet the requirements of high-rise buildings. Therefore, in this paper, a concrete sandwich thermal insulation composite wall with inclined reinforcement is proposed. The forms of inclined reinforcement include door frame and diamond. The quasistatic tests of four $1 / 2$ scale shear wall specimens are carried out to analyze their failure and mechanical properties, so as to provide the basis for the highrise engineering application of the composite wall.

\section{Testing Survey}

2.1. Testing Material. In this paper, four composite walls are designed, all using a $1 / 2$ scale model. Solid wall number is W01, the ordinary composite shear wall number is W02, the composite wall with door frame inclined tendon is W03, and the diamond-shaped inclined tendon composite wall is W04. The test walls are equipped with reinforced concrete base beams and loading beams. The composite wall specimen is composed of two concrete slabs with a compressive strength of C30 and a thermal insulation slab. The horizontal and vertical steel wire mesh adopts a cold-drawn low carbon steel wire with a diameter of $3.0 \mathrm{~mm}$, the longitudinal reinforcement is $\$ 12$, and the U-shaped reinforcement is $\$ 6$. The length of the wall edge component is $200 \mathrm{~mm}$ (see Figure 1). The remaining parameters of this experimental specimen are detailed in Table 1 . The actual force structure size of the solid wall and the composite shear wall is the same as the composite shear wall with the configuration of the inclined tendons.

2.2. Testing Device and Loading System. This experiment uses a quasistatic force test method with low-week cyclic loading [19]. Under the influence of a certain vertical load, a low-week cyclic horizontal load is applied to the top of the composite wall, and the loading of horizontal load is carried by a load and displacement hybrid control system. The test loading device and loading system are shown in Figures 2 and 3.

2.3. Test Results and Analysis. Through the observation and analysis of the test process, the four walls are subjected to force and then enter the elastic stage first, at which time the deformation is small; then, enter the elastic-plastic stage; at this time, the deformation of the wall gradually increased, and the wall appears horizontal bending shear cracks. With the further increase of the load, part of horizontal cracks run through and the tensile reinforcement yields. After entering the displacement control load, the wall and the wall on both sides of the base beam are crushed, then fall off, and the shear wall occurs bending shear failure. The failure mode of the four specimens is shown in Figure 4. The failure modes of the four walls shows that the horizontal bending shear cracks of the W01 and W02 are dense, the concrete on both sides of the wall and the foundation beam is damaged seriously, the W03 and W04 cracks of the specimen are sparse, and the concrete in the middle of the contact surface is spalling. Compared with the test specimens W03 and W04, the damage of the contact part between W03 and the foundation beam is more uniform and does not occur in the wall, while the concrete of W04 in the middle of the contact surface appears spalling. From the above analysis, it can be seen that W03 can effectively slow down the development of shear wall cracks, improve the comprehensive mechanical performance of shear wall, and improve the failure mode of composite wall, which is a good configuration form of inclined steel tendons. The configuration of diamond-shaped inclined tendons plays a certain role in limiting crack development.

\section{Seismic Performance Analysis of Specimens}

3.1. Hysteresis Curve Analysis of Specimen. The hysteresis curves of the four walls are shown in Figure 5, and the hysteresis curves are shown in Figure 6.

By comparing the hysteresis curves of the four walls, the shape is roughly the same. At the beginning stage, the area of residual deformation and hysteresis loop is small; at this time, the wall is in the elastic stage. With the increasing horizontal load, the area surrounded by the hysteresis loop increases, the energy consumption increases, and is roughly presented as a shuttle ring. After the peak load, the stiffness of the loading and unloading is clearly degraded, and the hysteresis curve has a certain degree of pinching phenomenon.

Comparing the test specimens W01 and W02, the number of W02 hysteresis loops is more and the hysteresis curve is fuller. After the horizontal stress reaches its peak, with the horizontal displacement increasing, the horizontal force decreases more smoothly. It indicates that the composite wall energy consumption capacity is better than the solid wall, and the stress performance is more stable. Compared with W02, W03, and W04, after reaching the ultimate load, with the increasing displacement, W03 is more stable to maintain the horizontal force slowly decreased; the wall stress performance is more stable, the hysteresis loop is also relatively full. From the hysteresis curve of W04 slips after reaching the limit load, the phenomenon of stagnant loop pinching is more obvious.

3.2. Analysis of Skeleton Curve and Stiffness Degradation of Specimens. The skeleton curve of the test specimen is shown in Figure 7, and the contrasting skeleton curve is shown in 

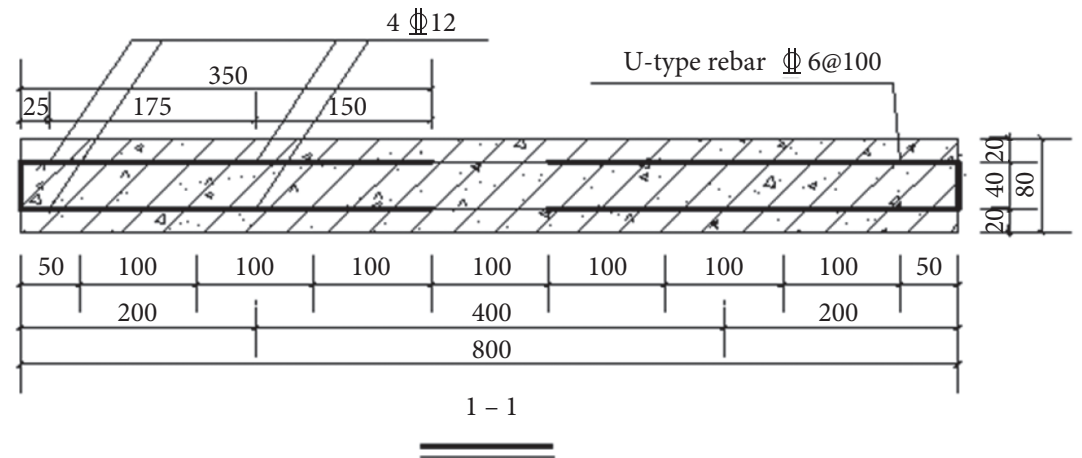

(a)

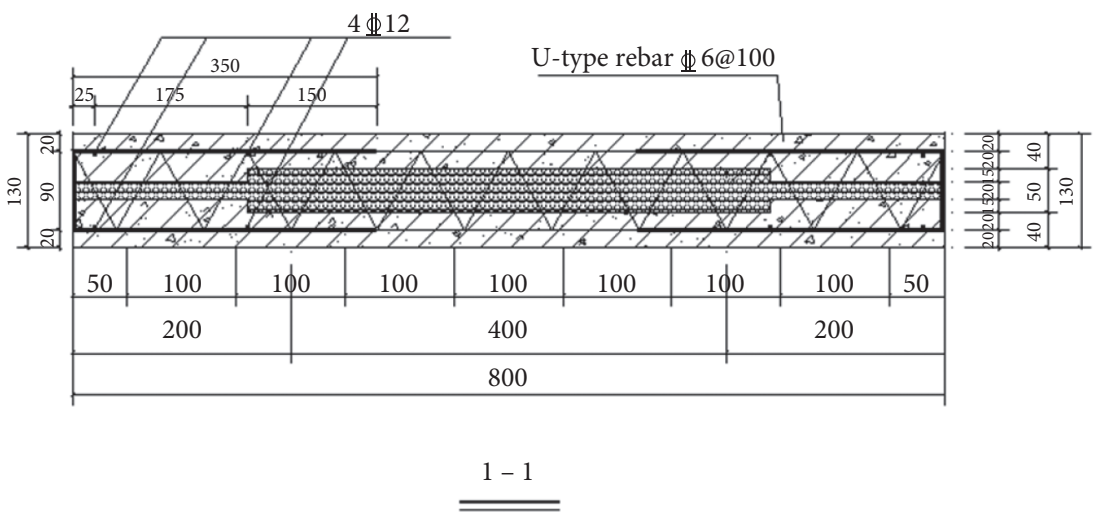

(b)

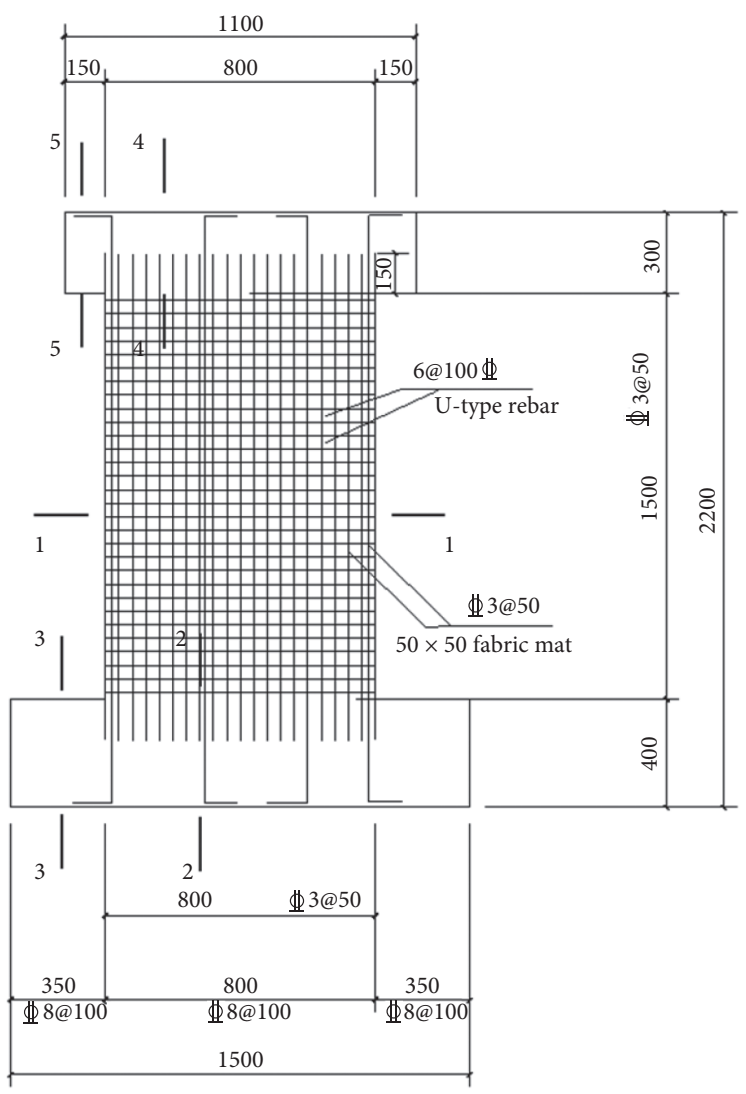

(c)

Figure 1: Continued. 


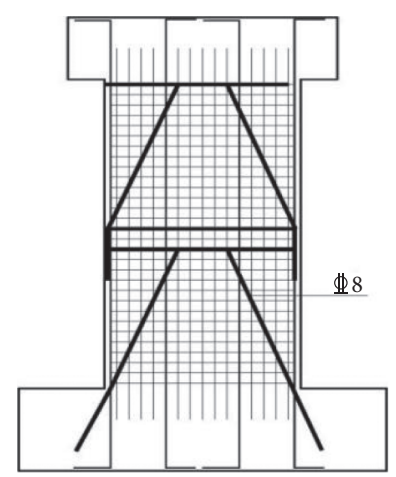

(d)

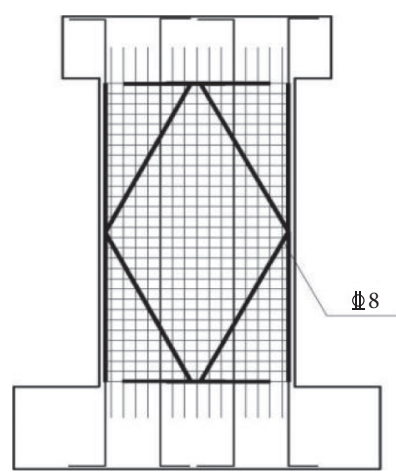

(e)

Figure 1: Composite wall size and reinforcement. (a) Section diagram of specimen W01 1-1. (b) Section diagram of specimen W02 1-1. (c) W01-W04 size reinforcement form. (d) W03 door frame inclined tendon. (e) W04 diamond-shape inclined tendon.

TABLE 1: Test piece overview.

\begin{tabular}{lccccc}
\hline $\begin{array}{l}\text { Test specimen } \\
\text { number }\end{array}$ & $\begin{array}{c}\text { Composite layer } \\
\text { thickness }(\mathrm{mm})\end{array}$ & $\begin{array}{c}\text { Thickness of border } \\
\text { composite layer }(\mathrm{mm})\end{array}$ & $\begin{array}{c}\text { Horizontal steel wire } \\
\text { reinforcement ratio }(\%)\end{array}$ & $\begin{array}{c}\text { Concealed } \\
\text { column section } \\
b \times h(\mathrm{~mm})\end{array}$ & $\begin{array}{c}\text { Longitudinal } \\
\text { reinforcement ratio }(\%)\end{array}$ \\
\hline W01 & 80 & 80 & 0.35 & $80 \times 200$ & 2.8 \\
W02 & $40+50+40$ & $55+20+55$ & 0.35 & $110 \times 200$ & 2 \\
W03 & $50+50+50$ & $65+20+65$ & 0.28 & $130 \times 200$ & 1.7 \\
W04 & $50+50+50$ & $65+20+65$ & 0.28 & $130 \times 200$ & 1.7 \\
\hline
\end{tabular}

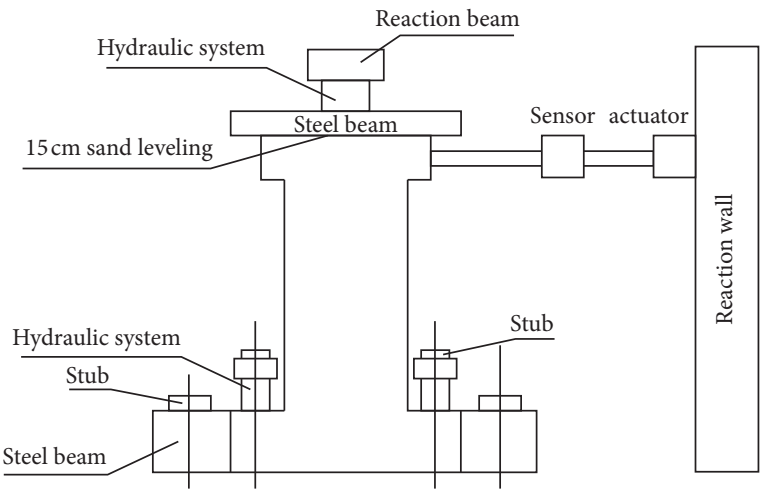

FIGURE 2: Loading device.

Figure 8. By comparing the skeleton curves of the four test specimens, it can be seen that the skeleton curves of each test specimen are roughly the same in the form of point symmetry, and there is no continuous mutation, which is a good elastic-plastic material. Before cracking, the skeleton curve is almost a straight line, showing obvious elastic characteristics. Except for the composite wall W04 with diamondshaped inclined tendons, the skeleton curve of the other three test specimens coincide, and the initial stiffness is similar; with the increasing load, the crack continues to develop and extend, and the stiffness of the test specimen decreases slowly. After the test specimen yields, the stiffness decreases further, and after entering the displacementcontrolled loading, the carrying capacity of each test specimen increases slowly, and the skeleton curve develops more

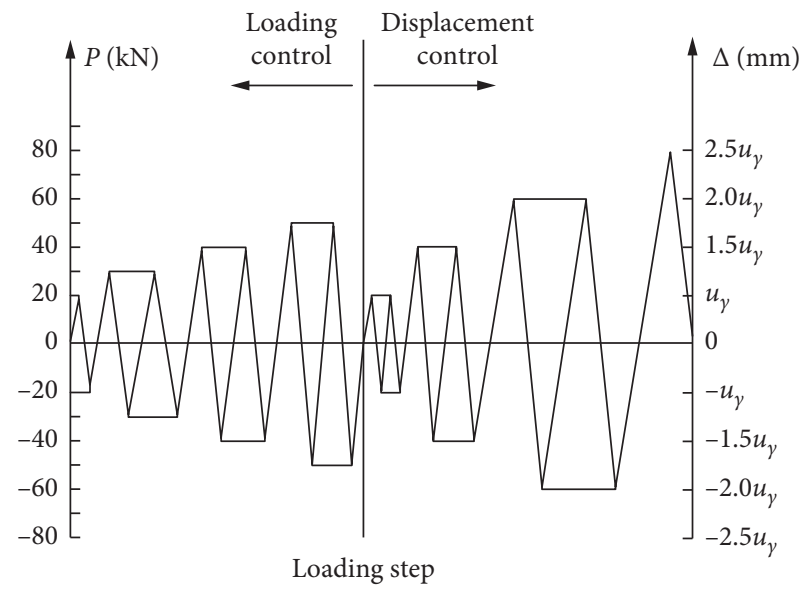

Figure 3: Loading system.

horizontally. After the test specimen reaches the ultimate bearing capacity, the stiffness decreases surely, the bearing capacity decreases to different degrees, and the test specimen loses the bearing capacity. Compared with the test specimens W02 and W01, the bearing capacity of the former is significantly higher than that of the latter, and the degradation of the later bearing capacity is more stable. Among them, the test specimen W02, W03, and W04 comparative analysis, W03's initial stiffness, yield strength, ultimate loading are larger, the late bearing stress is more stable, and after the test specimen reaches the limit load, the load drop is more moderate, and the stiffness degradation is slower. Although the initial stiffness of W04 has been improved, the stiffness 


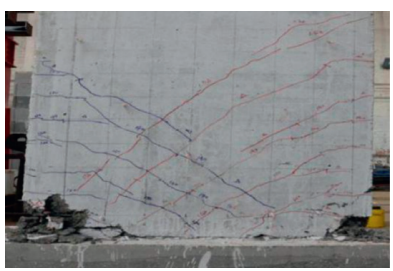

(a)

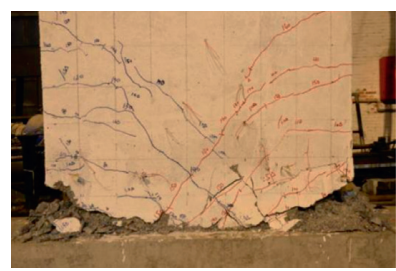

(b)

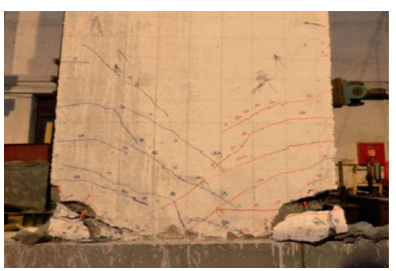

(c)

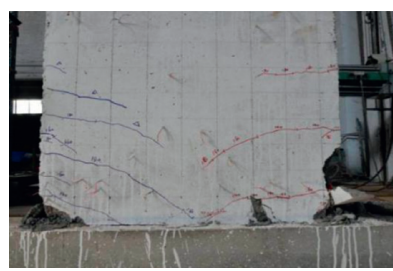

(d)

FIgUre 4: Test piece failure form. (a) W01. (b) W02. (c) W03. (d) W04.

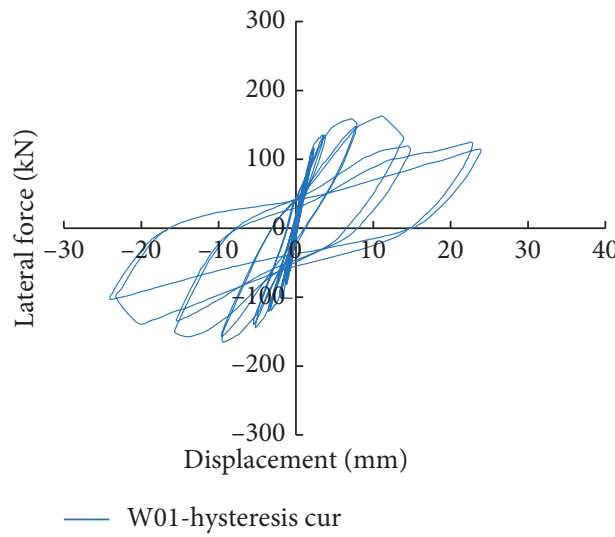

(a)

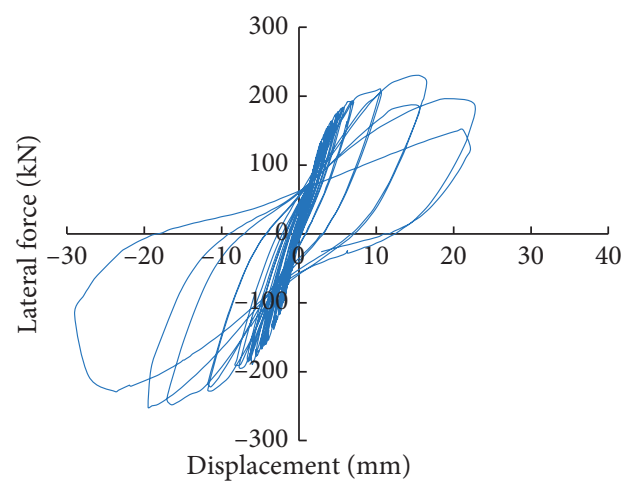

W03-hysteresis cur

(c)

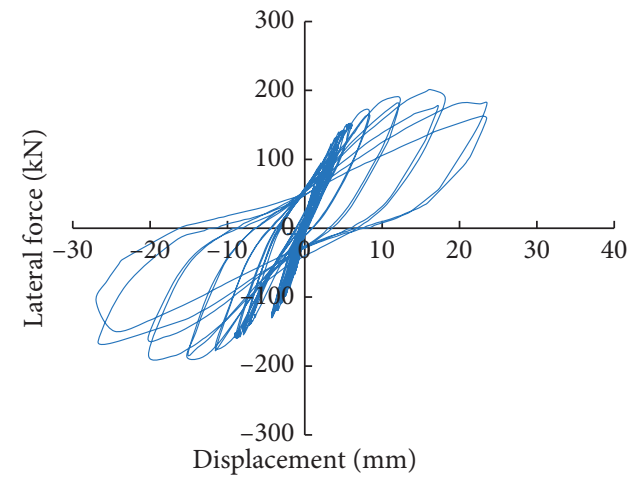

_ W02-hysteresis cur

(b)

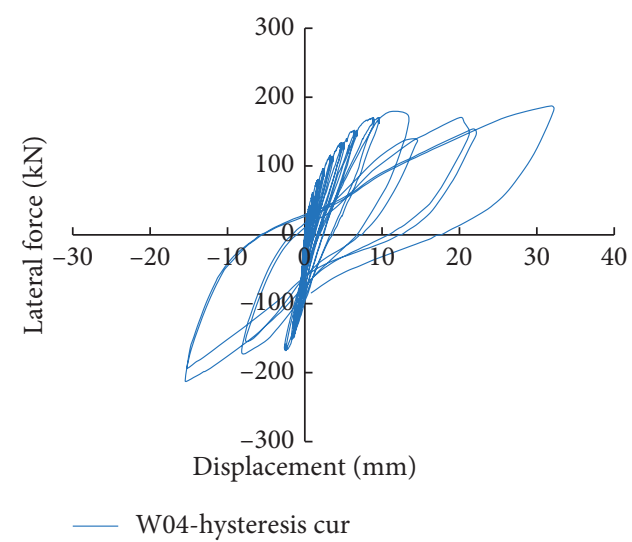

(d)

FIgure 5: Hysteresis curve of the test piece. (a) W01. (b) W02. (c) W03. (d) W04.

degradation after the cracking of the test specimen is obvious, and the carrying capacity of the test specimen is slightly improved compared to W02.

\subsection{Analysis of Skeleton Curve and Stiffness Degradation of} Specimens. Ductility is an important index to reflect structural deformation ability, and the common displacement ductility factor $\mu$ indicates the advantages and disadvantages of structural ductility [20]. The coefficient of ductility of the test specimen can be calculated by the following equation:

$$
\mu=\frac{u_{u}}{u_{y}},
$$

where $u_{c}$ is the cracking displacement corresponding to $F_{c}$, it is defined that the average displacement of the top of the wall under the action of low cycle horizontal load when the first crack appears; $u_{y}$ is the yield displacement corresponding to $F_{y} ; u_{u}$ is elastic-plastic limit displacement, it is defined that the horizontal carrying force drops to $85 \%$ of the peak horizontal force as the limit point, and if it does not drop to $85 \%$ of the peak horizontal force, the limit point is taken at the end of the test. The results of the calculation of the ductility coefficient of each test specimen can be found in Table 2 . 


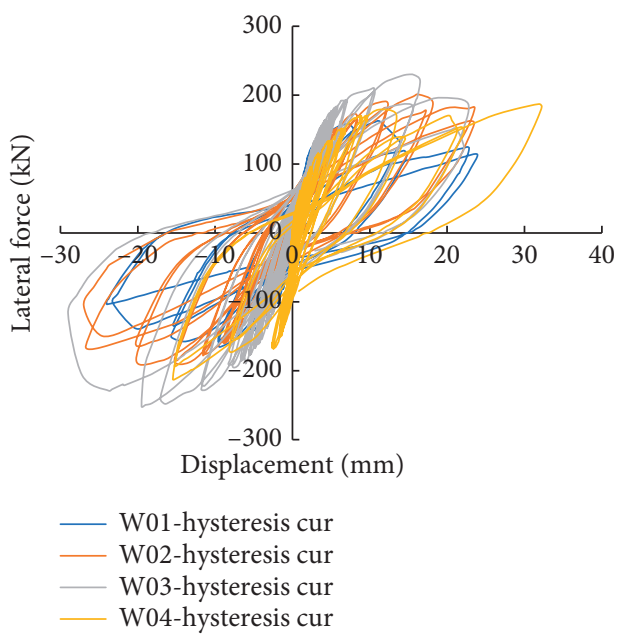

Figure 6: Test piece hysteresis curve comparison chart.

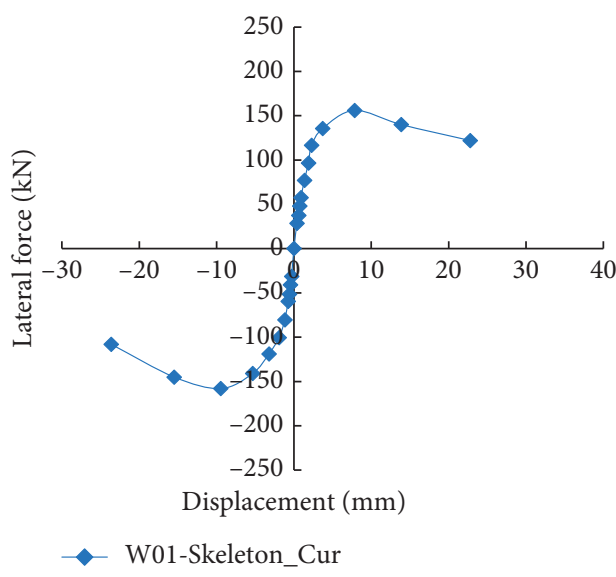

(a)

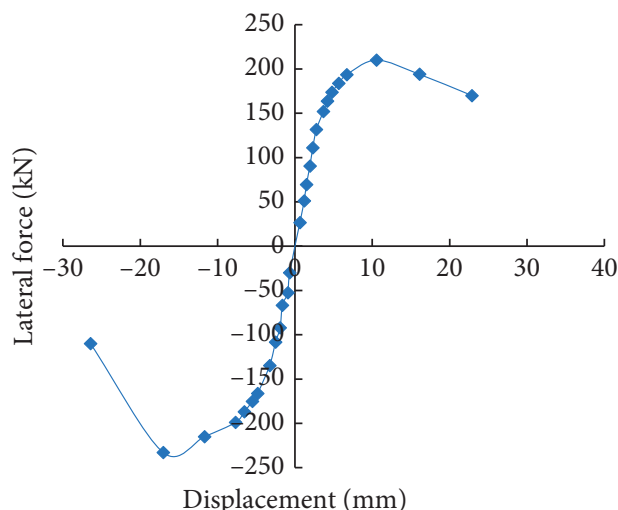

— W03-Skeleton_Cur

(c)

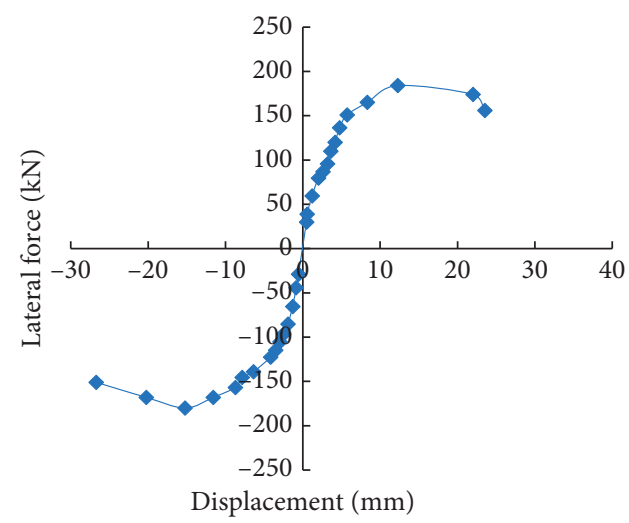

$\neg$ W02-Skeleton_Cur

(b)

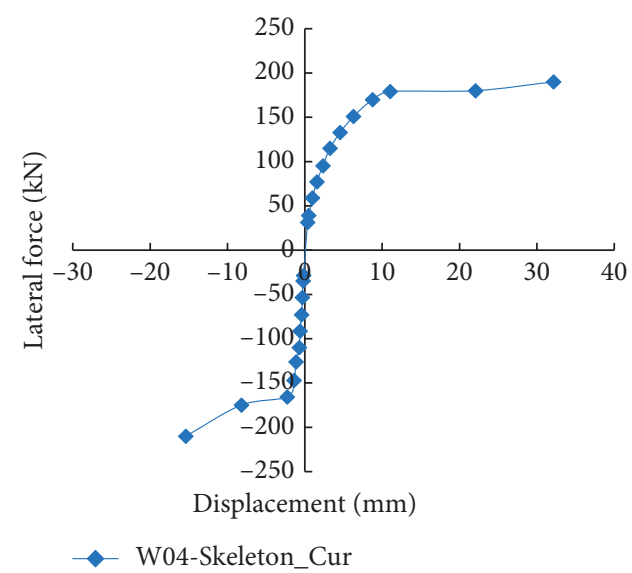

(d)

Figure 7: Skeleton curve of the test specimen. (a) W01. (b) W02. (c) W03. (d) W04. 


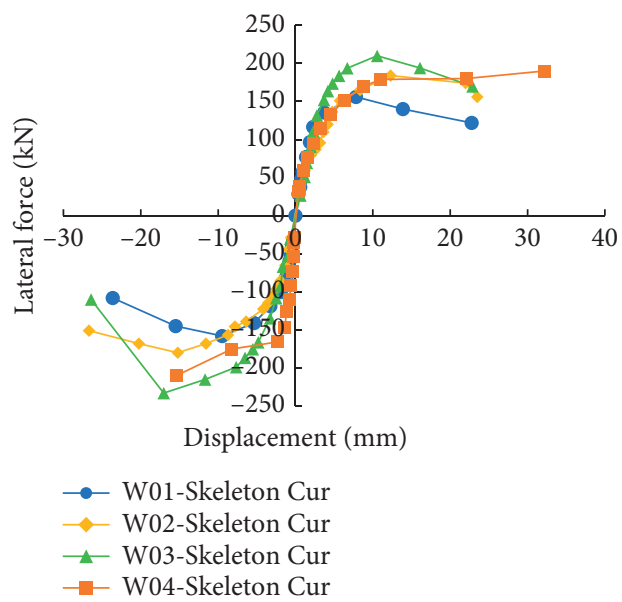

Figure 8: Skeleton curve comparison chart.

Table 2: Displacement ductility of test specimen.

\begin{tabular}{|c|c|c|c|c|c|c|c|}
\hline Location & Load input & $u_{c}(\mathrm{~mm})$ & $u_{y}(\mathrm{~mm})$ & Average of $u_{y}$ & $u_{u}(\mathrm{~mm})$ & Average of $u_{u}$ & $\begin{array}{c}\mu=\text { Average of } \\
u_{u} / \text { Average of } u_{y}\end{array}$ \\
\hline \multirow{2}{*}{ W01 } & Push & 0.90 & 3.46 & \multirow{2}{*}{4.4} & 13.43 & \multirow{2}{*}{14.46} & \multirow{2}{*}{3.29} \\
\hline & Pull & 0.79 & 5.34 & & 15.48 & & \\
\hline \multirow{2}{*}{ W02 } & Push & 0.46 & 4.17 & \multirow{2}{*}{5.58} & 18.12 & \multirow{2}{*}{19.17} & \multirow{2}{*}{3.43} \\
\hline & Pull & 0.56 & 6.99 & & 20.21 & & \\
\hline \multirow{2}{*}{ W03 } & Push & 1.06 & 3.49 & \multirow{2}{*}{3.99} & 14.41 & \multirow{2}{*}{17.72} & \multirow{2}{*}{5.08} \\
\hline & Pull & 1.06 & 4.49 & & 21.02 & & \\
\hline \multirow{2}{*}{ W04 } & Push & 0.37 & 6.04 & \multirow[b]{2}{*}{4.75} & 31.37 & \multirow{2}{*}{27.38} & \multirow{2}{*}{4.53} \\
\hline & Push & 0.90 & 3.46 & & 13.43 & & \\
\hline
\end{tabular}

Through the analysis of Table 2, it can be found that the ultimate displacement and displacement ductility factors of W03 and W04 have been effectively improved, indicating that the ductility performance of the wall is effectively improved by the configuration of inclined tendons, in the composite wall, of which W03 and W04 have increased by $48.10 \%$ and $32.07 \%$, respectively, and W03 has the greatest improvement. Overall, the W03 ductility performance is more stable for a better form of inclined tendon configuration.

3.4. Stiffness Degradation. The secant stiffness of the maximum displacement of each cycle under reciprocating horizontal load is defined as the equivalent stiffness [21], calculated using the following equation.

$$
K_{i}=\frac{\left|F_{i}\right|+\left|-F_{i}\right|}{\left|u_{i}\right|+\left|-u_{i}\right|},
$$

where $F_{i}$ is the $i$ th cycle peak horizontal force; $u_{i}$ is the $i$ th cycle peak level displacement, the positive sign represents forward loading, and the negative sign represents reverse loading. The average equivalent stiffness of each cycle under the same loading stage is taken as the equivalent stiffness of the specimen under this loading stage. Table 3 shows the measured values of the equivalent stiffness of each specimen, and Figure 9 shows the equivalent stiffness degradation curve. In Table $3, K_{\text {cr }}$ means cracking stiffness; $K_{y}$ means yield stiffness; $K_{p}$ means peak stiffness; and $K_{u}$ means ultimate stiffness.

The analysis shows that the stiffness degradation rule of each test specimen is consistent, the preloading stiffness degradation is faster, and with the advance of loading, the stiffness degradation gradually slows down. Comparing the test specimen W01 with W02, it can be known that the initial stiffness of the test specimen W02 is lower, but the later stiffness degradation is more stable and slow. The cracking stiffness of the test specimen W03 is low, but the stiffness of the test specimen is decreasing slowly after cracking, which indicates that the door frame inclined tendon has the effect of delaying the development of cracks; while the yield stiffness of W03 is indeed better than that of other test specimen, which indicates that the door frame-type inclined tendon has the effect of constraining the late deformation of the test specimen. The initial stiffness of the test specimen W04 is the largest of the four test specimens, which is about $60 \%$ higher than that of the test specimen W02; but its yield stiffness is small, which is due to the suspected insufficient length of the anchoring of the inclined tendons.

3.5. Energy Dissipation Capacity. By calculating the energy dissipation every half a week [22], the energy consumption capacity of the test specimen can be comprehensively 
TABLE 3: Measured value of specimen stiffness.

\begin{tabular}{|c|c|c|c|c|}
\hline Test specimen number & $K_{\mathrm{cr}}(\mathrm{kN} / \mathrm{mm})$ & $K_{y}(\mathrm{kN} / \mathrm{mm})$ & $K_{p}(\mathrm{kN} / \mathrm{mm})$ & $K_{u}(\mathrm{kN} / \mathrm{mm})$ \\
\hline W01 & 69.23 & 31.42 & 15.84 & 9.69 \\
\hline W02 & 61.35 & 23.34 & 12.19 & 8.91 \\
\hline W03 & 46.73 & 37.29 & 13.71 & 9.83 \\
\hline W04 & 101.26 & 18.00 & 7.73 & 5.57 \\
\hline
\end{tabular}

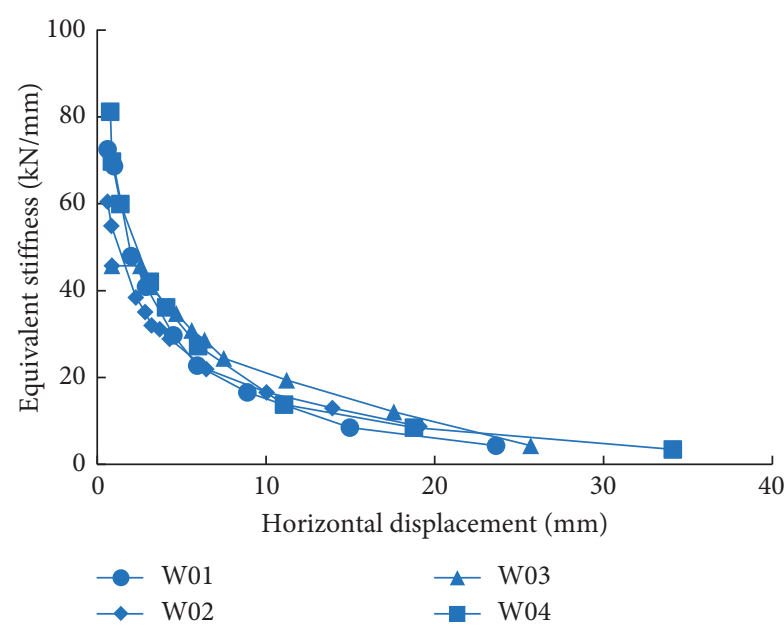

Figure 9: Equivalent stiffness degradation curve.

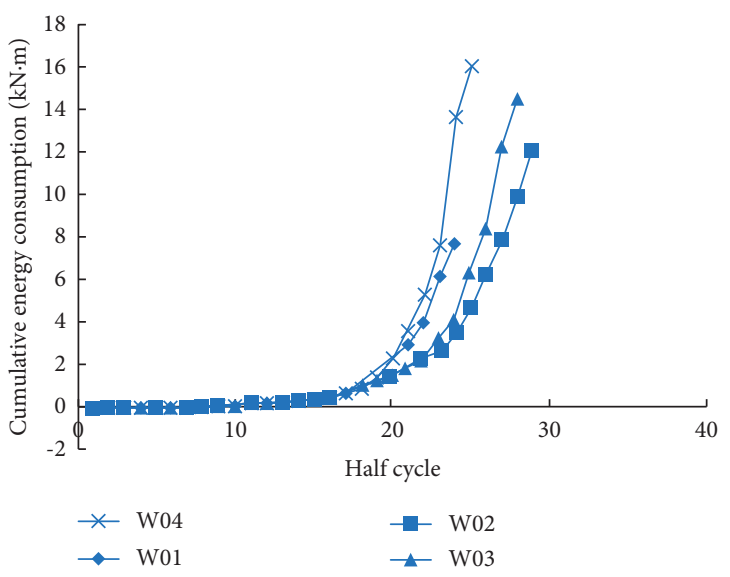

Figure 10: Cumulative energy consumption.

evaluated. The cumulative energy dissipation half-cycle curve of the specimen was calculated according to the horizontal load-displacement hysteresis curve of the specimen vertex, as shown in Figure 10.

The comparative analysis of the half-cycle cumulative energy consumption of each specimen shows that the energy consumption of each specimen is less in the elastic working stage. With the advancement of loading, the energy consumption of the specimen increases rapidly after entering the elastic-plastic stage. The cumulative energy dissipation of specimen W02 is higher than that of specimen W01, indicating that the energy dissipation capacity of the composite wall is better than that of the solid wall. The cumulative energy consumption of specimen W03 was $20 \%$ higher than that of specimen W02. The cumulative energy consumption of the specimen W04 is the highest. The energy consumption performance of the specimen W02 is significantly improved, indicating that the two inclined tendons are beneficial to the energy consumption performance of the composite wall.

\section{Conclusions}

Based on the analysis of the test results of four composite wall, this paper proves that the concrete sandwich insulation composite shear wall with door frame inclined tendon and diamond-shaped inclined tendon can effectively improve its mechanical performance and seismic performance, which provides ideas for the future design of composite wall. The results are as follows:

All four test specimens have gone through the elastic stage, the yield stage, the strengthening stage, and the destruction stage, and the final damage is the bending shear damage. The concrete spalling of the composite wall with door frame inclined tendon is less when it is damaged. The composite wall with diamond-shaped inclined tendon is inclined to shear failure, which is sudden to some extent.

The composite shear wall with inclined tendon has a certain effect on the stiffness degradation of the composite wall. The configuration of the door frame inclined tendon makes the composite shear wall more flat in the postloading stiffness drop, which has the effect of restricting the late deformation of the test piece. And, the configuration of diamond-shaped inclined tendon makes the initial stiffness of the composite wall greatly improved.

The configuration of inclined tendons makes the composite wall ductility performance have a certain degree of improvement, in which the configuration of door frame inclined tendon composite wall ductility performance is better.

The configuration of inclined tendons is beneficial to the energy consumption performance of the composite wall.

\section{Data Availability}

All the data used in this article are true and effective.

\section{Conflicts of Interest}

The authors declare no conflicts of interest.

\section{Acknowledgments}

This work was supported by the National Key R\&D Program (grant no. 2016YFC0701100); National Natural Science Fund (grant nos. 51678389 and 51508373); and Tianjin 
Natural Science Fund Key Projects (grant no. 16JCZDJC38900).

\section{References}

[1] X. F. Yao, "Research and development of new energy saving house structure system," in Proceedings of the 10th National Conference on Structural Engineering, vol. 1, Nanjing, China, 2001.

[2] D. C. Salmon, A. Einea, M. K. Tadros, and T. D. Culp, "Full scale testing of precast concrete sandwich panels," ACI Structure Journal, vol. 94, no. 4, pp. 354-362, 1997.

[3] T. D. Bush and Z. Q. Wu, "Flexural analysis of prestressed concrete sandwich panels with truss connectors," PCI Journal, vol. 43, no. 5, pp. 78-98, 1998.

[4] Y. T. Zhang, X. H. Zhang, M. Z. Wu et al., "Entative study on the aseismic behavior of sandwich wall with frame," Journal of Xi'an University of Architecture \&Technology, vol. 32, no. 3, pp. 209-212, 2000.

[5] Y. T. Zhang, Q. R. Yu, and M. Z. Wu, "Experimental study on carrying capacity of sandwich wall slab," Building Structure, vol. 31, no. 9, pp. 28-31, 2001.

[6] S. C. Li and Y. C. Wang, "Analysis on composite wall panels using finite element method," Building Structure, vol. 37, no. 7, pp. 50-53, 2007.

[7] W. L. Cao, H. Y. Dong, G. Z. Hu et al., "An exprimental study on the seismic behavior of rc coupled shear walls with concealed bracings of different styles," China Civil Engineering Journey, vol. 38, no. 8, pp. 18-25, 2005.

[8] W. L. Cao, X. M. Yang, J. W. Zhang et al., "Experimental study on seismic performance of RC shear wall with different types of composite concealed bracings," Journal of Building Structures, vol. 46, no. 1, pp. 33-40, 2007.

[9] Y. Z. Wang, Y. Huang, H. M. Wang et al., "Experiment research on seismic behavior of steel reinforced concrete shear walls of concealed bracings," Journal of Southwest Jiaotong University, vol. 53, no. 3, pp. 500-507, 2018.

[10] Y. Z. wang, X. H. Gao, D. J. Xu et al., "Experimental analysis on seismic performance of steel reinforced concrete shear wall with different types of steel bracings," Journal of Chongqing Jianzhu University, vol. 40, no. 5, pp. 44-53, 2018.

[11] M. F. Wang and Y. Q. Zhang, "Experimental study on seismic behavior of horizontal splicing precast composite shear wall with concealed bracings," Earthquake resistant engineering and Retrofitting, vol. 39, no. 50, pp. 102-111, 2017.

[12] M. D. Goel, V. A. Matsagar, S. Marburg et al., "Comparative performance of stiffened sandwich foam panels under impulsive loading," Journal of Performance of Constructed Facilities, vol. 27, no. 5, pp. 540-549, 2017.

[13] E. Hamed, "Modeling, analysis, and behavior of loadingcarrying precast concrete sandwich panels," Journal of Structural Engineering, vol. 142, no. 7, Article ID 04016036, 2016.

[14] K. Qian, P. He, N. Deng, and H. H. Li, "Impact of concrete strength on seismic behavior of T-shaped double-skin composite walls," Engineering Structures, vol. 236, Article ID 112039, 2021.

[15] Y. Qin, G. P. Shu, G. G. Zhou, and J. H. Han, "Compressive behavior of double skin composite wall with different plate thicknesses," Journal of Constructional Steel Research, vol. 157, pp. 297-313, 2019.

[16] S. Sabouri-Ghomi, A. Nasri, Y. Jahani et al., "Improved analytical formulation for steel-concrete (SC) composite walls under out-of-plane loads," Steel and Composite Structures, vol. 38, no. 4, pp. 463-476, 2021.

[17] S. Y. Kong, J. S. Fan, X. Nie, R. Ding, Y. L. Sun, and Y. Chen, "Pullout behavior of lap splice connections between doublesteel-plate composite walls and RC raft foundation in nuclear engineering," Engineering Structures, vol. 230, Article ID 111720, 2021.

[18] Y. Qin, C. Xin, X. Wang, Z. Xingyu, and C. Yuanze, "Behavior of L-shaped double-skin composite walls under compression and biaxial bending," KoreaScience, vol. 37, no. 4, pp. 405-418, 2020.

[19] National Standard of the People's Republic of China, Code for Seismic Design of Buildings ( 2016 edition ) ( GB50011-2010), China Architecture \& Building Press, Beijing, China, 2016.

[20] W. C. Xue, M. X. Zhu, Y. N. Liu et al., "Seismic performance of new precast concrete shear wall under high axial compression ratio," Journal of Harbin Engineering University, vol. 39, no. 3, pp. 452-460, 2018.

[21] J. R. Qian, X. K. Yang, H. Qin et al., "Tests on seismic behavior of pre-cast shear walls with various methods of vertical reinforcement splicing," Journal of Building Structures, vol. 32, no. 6, pp. 51-59, 2011.

[22] F. M. Bu, J. G. Nie, and J. S. Fan, "Experimental study on seismic behavior of medium and high shear-span ratio composite shear wall with double steel plates and infill concrete under high axial compression ratio," Journal of Building Structures, vol. 34, no. 4, pp. 91-98, 2013. 